\title{
What are the differences between physician and patient expectation with regard to the management of atrial fibrillation?
}

\author{
${ }^{1} \mathrm{MR}$ Fay, ${ }^{2} \mathrm{C}$ Montaňa \\ ${ }^{1}$ General Practitioner, Westcliffe Medical Practice, Shipley, West Yorkshire, UK; ${ }^{2}$ Research Fellow, Leeds Institute of Health Sciences, The University \\ of Leeds, Leeds, West Yorkshire, UK
}

\section{ABSTRACT}

Background: Atrial fibrillation (AF) is the most common sustained cardiac arrhythmia, with approximately 840,000 people suffering from it nationally. People with AF have an increased risk of stroke which can be mitigated effectively with the use of anticoagulant therapy. Nevertheless, evidence suggests that less than $50 \%$ of eligible patients are receiving this form of intervention.

Method: A comprehensive literature search was undertaken to assess the published evidence in order to understand why clinicians and patients underutilize an effective intervention such as anticoagulation in favor of the less effective antiplatelet agents.

Results: The decision to use anticoagulant drugs in patients with AF involves a consideration of the potential benefits versus the risks, inconveniences, and costs. There is however widespread variation in the importance placed on these factors across primary care practices, individual doctors and between and within different patient groups. There is a paucity of literature designed to examine patient expectations. Available studies suggest that patients are prepared to be placed at a higher risk of bleeding than their prescribing doctors would be prepared to accept. Given that this judgement depends on a range of factors, it is not surprising that attempts to understand clinician's barriers to prescribing take precedence.

Conclusion: The barriers to anticoagulation can be identified, but we still don't understand the importance that clinicians and individuals give them. These barriers continue to limit the use of anticoagulation therapy, a potentially beneficial treatment. Due to these limitations it is unclear what impact the increased range of oral anticoagulants and the alternation to the Quality and Outcomes Framework (QoF) will have on the incentive to primary care physicians to anticoagulate those at risk.

DECLARATION OF INTERESTS Dr Fay has served as a consultant for Boehringer Ingelheim, Bayer, Bristol Myers Squibb and Sanofi-Aventis.
Correspondence to M Fay

Westcliffe Medical Practice, Shipley, BDI 8 3EE, UK

matthew.fay@bradford.nhs.uk

\section{INTRODUCTION}

Atrial fibrillation (AF) is the most common sustained cardiac arrhythmia' and is a major risk factor for stroke. ${ }^{2}$ It has a national prevalence of $1.2 \%$, equating to 840,000 cases nationally, although many authorities would consider this an underestimation The prevalence of AF roughly doubles with each advancing decade of age, from $0.5 \%$ at age $50-59$ years to almost $9 \%$ at age $80-89$. It is estimated that $15 \%$ of all ischaemic stroke is due to atrial fibrillation, the majority of which is already identified prior to the stroke event. ${ }^{3-5}$

The published evidence has shown that oral anticoagulants ${ }^{6}$ and to a much lesser extent aspirin, ${ }^{7}$ can mitigate the rate of stroke in patients with $\mathrm{AF}^{8}{ }^{8} \mathrm{It}$ is estimated that long-term anticoagulation therapy can reduce the risk for stroke by approximately $68 \%$ per year in patients with non-valvular $\mathrm{AF}$, and even more in patients with valvular $\mathrm{AF}^{8,9}$
Despite evidence showing the benefit of anticoagulants, observational studies have consistently reported an overuse of antiplatelet agents and an apparent under-use of anticoagulant drugs in these patients. 10 The available data show that of those patients withAF and no contraindications to warfarin therapy, only $15 \%$ to $44 \%$ are prescribed warfarin. ${ }^{9,11-12}$ The unpublished Guidance on RiskAssessment and Stroke Prevention for Atrial Fibrillation (GRASP-AF) data shows this to be 15-64\% in England.

Reviews of patient records frequently reveal that only around $25 \%$ of patients meeting the criteria for anticoagulation are actually receiving it. Around $55 \%$ of these patients would still not be considered for anticoagulation even after a review, due to perceived contraindications. Another 20\% of patients indicated for treatment are not currently receiving it. A review of patient records can often trigger changes to their treatment. ${ }^{13}$ 
MR Fay, C Montaňa

\section{LITERATURE OVERVIEW}

A comprehensive review of barriers to warfarin use in AF published by Ingelgard et al in 2006 captures much of what is currently known about factors influencing prescribing decisions, ${ }^{14}$ (see Annex $A$ for list of barriers and Annex $B$ for a critique of the paper). These barriers are internationally identified, coming mainly from the USA, Australia, Canada and mainland Europe. Known barriers can be described under four main themes including: I) medical characteristic factors; 2) patient ability to take the treatment and adhere to monitoring requirements; 3) patient preferences; and 4) healthcare system barriers. The barriers to prescribing in the UK may be the same but this is not known for certain.

It is clear that the decision to use anticoagulant drugs in patients with AF involves a consideration of the potential benefits versus the risks, inconveniences, and costs. ${ }^{15-19}$ There is however widespread variation in the importance placed on these factors across primary care practices, individual doctors and between and within different patient groups. There is also a lack of agreement on the legitimacy of cited contraindications to prescribing, such as risk of falls or age of patients. ${ }^{20}$

The extent to which each or all of these factors influence prescribing decisions and treatment is not known, although assessment of risk (haemorrhage or bleeding episode) is a key factor. However, there are wide variances in the thresholds for assessment of risk both between and within studies. ${ }^{21}$ Physicians who see higher numbers of patients with $\mathrm{AF}$ are prepared to take more risks regarding anticoagulation ${ }^{21,22}$ although more experienced practitioners, i.e. cardiologists, overestimate the benefit of using anticoagulation drugs in low-risk patients. ${ }^{23}$ Increased experience as a registered medical practitioner however is generally related to poorer performance on classifying patients according to risk of stroke. ${ }^{23}$ GPs in the UK tend to overestimate both the number of their patients who meet eligibility thresholds for anticoagulant therapy and also the number of their patients currently receiving warfarin. ${ }^{13,24}$

At the same time, attempts to change prescribing practices, for example the introduction of quality indicators, ${ }^{25}$ education including knowledge and skills training, ${ }^{26}$ computerised feedback ${ }^{27}$ (although this has been criticised as consultation outcomes often need to vary from the decision support software's recommendations ${ }^{28}$ ), risk reduction strategies such as patient-specific information aids to help prescriber decision-making i.e. Mini Mental State Examination (MMSE) to help with cognition rating ${ }^{29}$ and shared decision-making, ${ }^{30}$ paced information with the opportunity to check understanding at a later time, ${ }^{29}$ and the introduction of practice-specific protocols ${ }^{13}$ all show some success, although they are often limited to the specific setting, with little sustainability or generalisability.
One possible reason for these difficulties is that perhaps we do not fully understand the behavioural determinants (constructs which affect behaviour) prior to initiating interventions aimed at behavioural change, or even know that the constructs are amenable to change; hence the intervention may not be delivered through the most relevant behaviour change technique available. ${ }^{31}$

Perhaps we will see improvements in the proportion of eligible patients receiving anticoagulants now that alternatives to warfarin exist. Two licensed agents are now available in the form of the direct thrombin inhibitor, dabigatran and the factor $\mathrm{Xa}$ inhibitor rivaroxaban, and a further Xa inhibitor, apixaban will soon come to market. All three agents have been shown to be non-inferior to warfarin however all have also demonstrated a lower intercerebral bleed rate. These drugs will be more convenient in clinical use as there is no need for regular assessment of their anticoagulant effect and have set dosing (although some advice is required for dose adjustment if given for impaired renal function and extreme age). However they are not without risk if not used correctly and dabigatran in particular is very expensive. Most healthcare organisations across the UK have produced guidelines to encourage cost beneficial use. There is good reason therefore to believe that most of the impetus for management (or lack of management) of atrial fibrillation comes from GPs and hospital doctors; whether patients are offered treatment or not depends largely on their skills and abilities. We know that patients find this decision complex and there are reasons why they might justifiably avoid an effective treatment; however, many inappropriate variations in practice cannot be explained by patient expectations. We need to obtain a better understanding of how we can encourage more doctors to offer anticoagulants as a treatment option.

The literature is not presented in a way that facilitates current understanding of why and how patients remain under-treated. Previous research attempts have focused on identifying the barriers to warfarin use and preferences for treatment options, ${ }^{32-34}$ while widespread consultation with key prescribers and patients on how to improve warfarin use and its day-to-day management is lacking. Research to date mainly consists of retrospective cohort analysis and observational studies, prospective observational studies, point-prevalence studies, literature reviews and medical record and chart reviews, patient quality of life surveys and cross-sectional postal surveys and questionnaires (many of which involve the use of clinical vignettes). However, asking prescribers (usually doctors) whether they would apply barriers to specific case examples, or asking them about the reluctance to prescribe if a barrier is theoretically present, are artificial scenarios and respondents give answers that are expected. We do not know how these barriers are applied in real life scenarios. There is some evidence supporting the idea that intention varies from actual 
treatment. ${ }^{16} \mathrm{~A}$ systematic review published earlier this year focuses on the attitudes of physicians towards anticoagulation but relies on self-reported practice and fails to include qualitative literature within their scope. It could be argued based on these studies, that it is only when we speak to GPs about specific patients that are eligible but not given warfarin that we begin to understand the interplay between known barriers and treatment decisions.

\section{QUALITATIVE LITERATURE}

\section{Summary}

\section{GP interviews}

I Lipman T, Murtagh MJ, Thomson R. How researchconscious GPs make decisions about anticoagulation in patients with atrial fibrillation: a qualitative study. Fam Pract 2004; 21:290-8. ${ }^{22}$

Lipman et al were interested in how GPs with an active interest in research and evidence-based medicine make decisions about anticoagulation in patients with AF. They conducted semi-structured interviews with II GPs. A constructivist approach was taken to analysis and interpretation. Two key themes materialised: evidence and professional role. Key findings were:

- There is wide variation in perception of the evidence, which is influenced by experience, attittudes and variable knowledge of the literature.

- Shared decision-making with the patient is paramount and this often results in antagonism towards prescriptive clinical guidelines.

- Hospital doctors have a strong influence on decisionmaking, and they are often seen as difficult to challenge and poor at communicating.

2 Short D, Frischer M, Bashford J.The development and evaluation of a computerised decision support system for primary care based upon 'patient profile decision analysis'. Inform Prim Care 2003; I I:195-202. ${ }^{35}$

Short et al were interested in developing and designing a computerised decision support system for the management of stroke patients. The same $15 \mathrm{GPs}$ in the study above underwent a second qualitative interview and questionnaire after having access to the support system. Hypothetical patient vignettes were used and it was determined that GPs were more certain about their decision-making, which was more in line with national guidelines. However, it is still not clear how this support system would be used in a real life scenario, although GPs felt that it would improve their dialogue with patients.

3 Oswald N, Bateman H.Treating individuals according to evidence: why do primary care practitioners do what they do? J Eval Clin Pract 2000; 6: I39-48. ${ }^{13}$
Oswald and Bateman observed the process of practitioners assimilating research evidence. In this study, lead GPs from six different practices provided information on the practicalities of agreeing a practice protocol and implementing it. Key findings include:

- Judgement over what constitutes a 'key source' to which reference must be made before a protocol is developed varies between practices and practitioners. The amount of time required to access information and the confidence in the appraisal of research papers also differs; the applicability of evidence to individuals under their care varies; the level of confidence in the lack of harm was different for everyone. There were also doubts about the durability of current research evidence. Harmonising with guidance from local specialists was also a challenge. GPs also rated published research evidence differently.

- There were variations in the assessment of risk, particularly for aspirin (doctors may have a lower threshold of what constitutes risk than that documented in studies). GPs believe that the decision is explicitly at the doctor's discretion. There was disagreement over the criteria for referral for specialist opinion. The explicit involvement of patients and carers in decision-making was also a topic of debate.

- There were practical difficulties in maintaining momentum and doubts about the value of the enterprise and the sustainability of the proposed protocol.

- Reasons for not prescribing warfarin for patients were included, although their patient samples were not typical of under-warfarinisation rates reported in other studies, i.e. in this study three-quarters of those eligible were being given warfarin:

॥ Prior medical knowledge of physicians

॥ Opinions of patients and others (i.e. local specialists)

1) A practitioner's opinions around quality of life issues and whether individuals are covered by the protocols.

Secondary care interviews

I Anderson N, Fuller R, Dudley N. 'Rules of thumb' or reflective practice? Understanding senior physicians' decision-making about antithrombotic usage in atrial fibrillation. QJM 2007; 100:263-9. ${ }^{36}$

Anderson et al were interested in understanding physicians' behaviour and attitudes in decision-making about AF and the use of antithrombotics. They used a semi-qualitative questionnaire and an interview-based approach with 14 senior clinicians, and analysed the results using grounded theory (although closer inspection of the article reveals that the term is used loosely for the purposes of this study). Each participant was presented with five clinical vignettes illustrating a range of risks and 
MR Fay, C Montaňa

benefits to antithrombotic treatment choices for $\mathrm{AF}$ and stroke prevention. There was marked variation in levels of uncertainty and doubt about risks versus benefits, concerns about knowledge, and the role of the patient in decision-making. However, the level of information given in the vignettes was often not enough for clinicians to make an informed decision, a criticism that has been levied at other studies using similar methods. ${ }^{16}$

\section{Group interviews}

I Bajorek BV, Ogle SJ, Duquid MJ et al. Management of warfarin in atrial fibrillation: views of health professionals, older patients and their carers. Med J Aust 2007; |86: $175-80 .^{31}$

Bajorek et al were interested in identifying health professionals, patients and their carer's views on strategies to improve the use and management of warfarin in older patients with AF. They used group interviews involving 14 patients, six community pharmacists, nine hospital pharmacists, three carers, 12 specialists, eight GPs and II nurses. Key barriers to use and management included:

- Appropriateness of guidelines to GP caseloads.

- Support services for GPs and patients, including dissemination of evidence to GPs and enlisting allied health professionals in patient management.

- Availability and appropriateness of information for patients.

2 Bajorek BV, Krass I, Ogle SJ et al.Warfarin use in the elderly: the nurses' perspective. Aust J Adv Nurs 2006; 23: 19-25. ${ }^{37}$

Bajorek et al explored the barriers to warfarin use from the perspective of nurses working in elderly care. A semi-structured group interview was conducted with II nurses, and the results underwent a thematic analysis. Five main themes were identified: perceived patient attitude towards warfarin, barriers to the use of warfarin, expressed lack of confidence in the processes involved, nurses' role in warfarin use, and strategies to improve warfarin use. They concluded that nurses feel that they have limited capacity to intervene and that they are a potentially underutilised resource for both patient support and prescribers.

\section{Patient interviews}

I Dantas GC, Thompson BV Manson JA et al. Patients' perspectives on taking warfarin: Qualitative study in family practice. BMC Fam Pract 2004; 5:15. ${ }^{38}$

This study used face-to-face interviews with 21 older patients who had been taking warfarin for a minimum of six months. Participants were patients at a family practice clinic situated in a large, tertiary care teaching hospital. A semi-structured interview guide covering four main thematic areas was used: decision-making, knowledge/ education, impact and satisfaction. Data were analysed according to the principles of content analysis. Main findings include:

- Patients tended to have minimal input into the decision to initiate warfarin therapy, instead relying largely on the physicians' expertise.

- There appeared to be low retention of information about the therapy; half the patients in the sample had only a superficial level of understanding of the risks and benefits.

- Patients reported a high level of satisfaction with the care provided and a low level of impact on their day-to-day lives.

\section{BEHAVIOURAL DETERMINANTS}

Factors such as knowledge, level of skills, social/ professional role and identity and beliefs about capabilities are well-documented in qualitative literature. Awareness of guidelines and recommendations is not enough to influence practice. There are a number of elements that influence what GPs think about the evidence e.g. attititude, credibility, beliefs in the extent to which it should influence behaviour and compatibility with professional standards and identity. There are also differences in how GPs view the consequences of treatment to themselves and their patients (and their beliefs about patient capabilities). Social influences such as power and hierarchy within the healthcare system must also be considered. There is a lack of clarity over the influential nature of different professionals within the entire system: hospital doctors have 'power' over GP prescribing decisions; nurses with ill-defined and variable roles within warfarin management plans.

The environmental context and resources available are also issues i.e. time constraints and lack of systems for monitoring and reviewing patients (although the extent to which these factors influence prescribing is also influenced by the GP's attitude/beliefs about priorities for their patient). It has been suggested that computerised decision-making tools may help to focus GP/patient dialogue within the reality of time constraints, although the inflexibility inherent within these systems limits behaviour. Inability to work closely with other colleagues and competing time constraints are also a factor; likewise a reluctance to send more patients to attend hospital clinics and a lack of resources to assist with practicebased supervision are also important issues.

The applicability and appropriateness of information available for patients (how the GP conveys this information, the accuracy of it and/or the patient's understanding) will also influence treatment. Information on patient resistance to treatment is rarely referred to within the present literature, indicating that this may be 
lacking (although this was not a search parameter for our purposes). Devereaux et al demonstrated that patients at high risk of $A F$ place more value on the avoidance of stroke and less value on the avoidance of bleeding than the physicians who treat these patients, ${ }^{21}$ thus indicating that even if risk factors are known, the patient's knowledge and belief about these risk factors is as important as the doctor's beliefs to the management outcome. Shared decision-making is seen as necessary within the literature although we are not clear about what factors facilitate and/or hinder this process in warfarinisation..$^{39,40}$

The motivation for and the aims of preventative medicine are rarely discussed within the literature, particularly in terms of how little benefit GPs can see from their efforts. Any harm on the other hand remains visible and carries practical consequences for the doctor and patient. In the Oswald study, ${ }^{13} 27$ patients could be prescribed warfarin, preventing I-2 strokes per year. Even if the full benefit from anticoagulation were felt within her/his population, a GP's application of evidence will prevent a few strokes, of which, by definition he/she will be unaware. Finally, assessment of risk is a key factor in determining prescribing decisions and yet the profound psychological dimension to this decision is rarely addressed in the literature in a way that brings this to the forefront of our thinking about behavioural determinants. ${ }^{41,42}$

\section{WHAT IS NOT KNOWN}

Barriers to anticoagulation therapy are known, but not the extent to which each applies.

- Where the barriers are found is not known e.g. do they lie primarily with GPs or hospital doctors. There may be unknown obstacles that apply to healthcare management in the NHS, such as lack of ownership of the problem by primary or secondary care. ${ }^{43}$ Hospital specialists are often included in research into barriers ${ }^{44}$; examination of the level of congruence/divergence between hospitals and GPs in terms of treatment is missing (although the scoping work search did not necessarily include studies from secondary care at this stage).

- We do not know how the barriers apply to real life scenarios.

- We lack data on patient objections to being prescribed warfarin, although their preference is a key determinant. Differences in preferences are difficult to predict, vary in direction and magnitude and are often specific to a particular condition. ${ }^{21}$

- We have yet to see the impact that recently introduced prescribing indicators has on prescribing practice.

- We don't know the extent to which a stroke risk stratification algorithm is actually used in practice.

- There may be differences and similarities between barriers to initiating prescription and unsuccessful dose maintenance.
- The extent to which patient samples in clinical trials represent clinical caseloads of GPs is not known.

- Research on cultural/ethnic barriers to prescribing is also required.

- Studies of patients recently prescribed warfarin are missing from the literature.

\section{CONCLUSION}

Despite a large amount of evidence showing the link between AF and ischaemic stroke, steadily increasing evidence regarding the benefits of anticoagulation and the development of tools to stratify risk, the uptake in those who would benefit from anticoagulation therapy remains poor.

The barriers to anticoagulation can be identified, but we still don't understand the importance that clinicians and individuals give them. These barriers continue to limit the use of anticoagulation therapy, a potentially beneficial treatment.

\section{REFERENCES}

I Cuddy TE, Connolly SJ. Atrial fibrillation and atrial flutter. Can J Cardiol 1996; 12:9A-IIA.

2 Wolf PA,Abbott R, KannelWB.Atrial fibrillation as an independent risk factor for stroke: the Framingham study. Stroke 1991; 22:98388. http://dx.doi.org/ 10.1 I6I/0 I.STR.22.8.983

3 National Collaborating Centre for Chronic Conditions. Atrial Fibrillation: national clinical guideline for management in primary and secondary care [Internet]. London: Royal College of Physicians; 2006 [cited 20II Dec 2I]. Available from: http://www.nice.org.uk/ nicemedia/live/ 10982/30055/30055.pdf

4 Stewart S, Hart CL, Hole DJ et al. Population prevalence, incidence, and predictors of atrial fibrillation in the Renfrew/Paisley study. Heart 200I; 86:5 I6-2I. http://dx.doi.org/10.1 I36/heart.86.5.516

5 DeWilde S, Carey IM, Emmas $C$ et al. Trends in the prevalence of diagnosed atrial fibrillation, its treatment with anticoagulation and predictors of such treatment in UK primary care. Heart 2006; 92: 1064-70. http://dx.doi.org/10.1 136/hrt.2005.069492

6 [No authors listed]. Risk factors for stroke and efficacy of antithrombotic therapy in atrial fibrillation. Analysis of pooled data from five randomized controlled trials. Arch Intern Med 1994; 154:1449-57.http://dx.doi.org//0.100 I/archinte.1994.00420130036007

7 [No authors listed]. The efficacy of aspirin in patients with atrial fibrillation. Analysis of pooled data from 3 randomized trials. The Atrial Fibrillation Investigators. Arch Intern Med 1997; I57: 1 237-40. http://dx.doi.org/I0.100I/archinte.1997.00440320143013

8 Aguilar MI, Hart R, Pearce LA. Oral anticoagulants versus antiplatelet therapy for preventing stroke in patients with nonvalvular atrial fibrillation and no history of stroke or transient ischemic attacks. Cochrane Database Syst Rev 2007; I8: CD006I86.

9 Bungard TT, Ghali WA, Teo KK et al. Why do patients with atrial fibrillation not receive warfarin? Arch Intern Med 2000; 160:4I-6. http://dx.doi.org/10.1001/archinte.160.1.4I

10 Connolly SJ.Preventing stroke in atrial fibrillation: why are so many eligible patients not receiving anticoagulant therapy? CMAJ 1999; I61:533-4. 
MR Fay, C Montaňa

II MajeedA, Moser K, Carroll K.Trends in the prevalence and management of atrial fibrillation in general practice in England and Wales, 1994-1998: Analysis of data from the general practice research database. Heart 200I; 86:284-8. http://dx.doi.org/I0.1 I36/heart.86.3.284

12 Cowan C, Fay M, Griffith K et al. Anticoagulation in AF. Anticoagulation uptake remains poor in high risk patients. BMJ 20I I;342:d I 53. http:// dx.doi.org/10.1 136/bmj.dII 53

I3 Oswald N, Bateman H. Treating individuals according to evidence: why do primary care practitioners do what they do? J Eval Clin Pract 2000; 6: I39-48. http://dx.doi.org/ I0.1046/j. I365-2753.2000.00243.x

14 Ingelgard A, Hollowell J, Reddy $P$ et al. Barriers to warfarin use in atrial fibrillation?: development of a questionnaire. J Thromb Thrombolysis 2006; 2 I:257-65. http://dx.doi.org/|0.1007/s | |239-006-5633-2

15 Brass LM, Krumholz HM, Scinto JM et al. Warfarin use among patients with atrial fibrillation. Stroke 1997; 28:2382-89. http:// dx.doi.org/10.1 I6I/0I.STR.28.12.2382

16 Sudlow M, Rodgers H, Kenny R et al. Population based study of use of anticoagulants among patients with atrial fibrillation in the community. BMJ 1997; 3 14:1529-30. http://dx.doi.org//0.1 I36/bmj.3 |4.7093.1529

17 Whittle J, Wickenheiser L, Venditti LN. Is warfarin underused in the treatment of elderly persons with atrial fibrillation? Arch Intern Med 1997; I57:44|-5. http://dx.doi.org/ I0.100 I/archinte. 1997.004402500970 I |

I8 [No authors listed]. Thromboembolic prophylaxis in 3575 hospitalized patients with atrial fibrillation (CQIN). Can J Cardiol 1998; 14:695-702.

19 Antani MR, Beyth JR, Covinsky KE et al. Failure to prescribe warfarin to patients with nonrheumatic atrial fibrillation. J Gen Intern Med 1996; I I:7 I3-20. http://dx.doi.org/ I0.1007/BF02598984

20 Dow L, Bertagne B. Anticoagulation in patients with atrial fibrillation. Underuse of warfarin is multifactorial. BMJ 1993 307:1492-3. http://dx.doi.org/10.1 I36/bmj.307.69/7.1492-a

21 Devereaux PJ, Anderson DR, Gardner MJ et al. Differences between perspectives of physicians and patients on anticoagulation in patients with atrial fibrillation: observational study. BMJ 200I; 323: I 1 |8-22. http://dx.doi.org/I0.1 |36/bmj.323.7323.1218

22 Lipman T, Murtagh MJ, Thomson R. How research-conscious GPs make decisions about anticoagulation in patients with atrial fibrillation: a qualitative study. Fam Prac 2004; 21:290-8. http:// dx.doi.org// 0.1093/fampra/cmh313

25 Peterson GM, Boom K, Jackson S et al. Doctors' beliefs on the use of antithrombotic therapy in atrial fibrillation: identifying barriers to stroke prevention. Intern Med J 2002; 32:15-23. http://dx.doi. org/I0.1046/j. I445-5994.2002.00I56.x

24 Oswald N, Bateman $\mathrm{H}$. Applying research evidence to individuals in primary care: a study using non-rheumatic atrial fibrillation. Fam Pract 1999; 16:4 I4-9. http://dx.doi.org//0.1093/fampra//6.4.4I4

25 McGovern MP, Boroujerdi MA, Taylor MW et al. The effect of the UK incentive-based contract on the management of patients with coronary heart disease in primary care. Fam Pract 2008; 25:33-9. http://dx.doi.org/10.1093/fampra/cmm073

26 Mandryk JA, Wai A, Mackson JM et al. Evaluating the impact of educational interventions on use of antithrombotics in Australia. Pharmacoepidemiol Drug Saf 2008; 17:160-7I. http://dx.doi. org/10.1002/pds. I536

27 Naughton C, Feely J, Bennett K.A clustered randomized trial of the effects of feedback using academic detailing compared to postal bulletin on prescribing of preventative cardiovascular therapy. Fam Pract 2007; 24:475-80. http://dx.doi.org//0.1093/fampra/cmm044
28 de Lusignan S, Singleton A,Wells S. Lessons from the implementation of a near patient anticoagulant monitoring service in primary care. Inform Prim Care 2004; 12:27-33.

29 Bajorek BV, Ogle SJ, Duquid MJ et al. Management of warfarin in atrial fibrillation: views of health professionals, older patients and their carers. Med J Aust 2007; 186:175-80.

30 Protheroe J, Fahey T, Montgomery AA et al. The impact of patients' preferences on the treatment of atrial fibrillation: Observational study of patient based decision analysis. BMJ 2000; 320:1380-4. http://dx.doi.org//0.1 I36/bmj.320.7246.1380

3I Michie S, Johnston M, Francis J et al. From theory to intervention: Mapping theoretically derived behavioural determinants to behaviour change techniques. Applied Psychology 2008; 57:660-80. http://dx.doi.org/ I0. I I I I/j. I464-0597.2008.0034I.x

32 McCrory DC, Matchar DB, Samsa G et al. Physician attitudes about anticoagulation for nonvalvular atrial fibrillation in the elderly. Arch Intern Med 1995; 155:277-8I. http://dx.doi.org/l0.100I/ archinte. 1995.00430030071008

33 Man-Son-Hing M, Laupacis A, O'Connor A et al.Warfarin for atrial fibrillation: the patient's perspective. Arch Intern Med 1996;

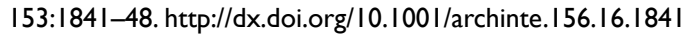

34 Monette J, Gurwitz JH, Rochon PA et al. Physician attitudes concerning warfarin for stroke prevention in atrial fibrillation: results of a survey of long-term care practitioners. J Am Geriatr Soc 1997; 45:1060-5.

35 Short D, Frischer M, Bashford J et al. Why are eligible patients not prescribed aspirin in primary care? A qualitative study indicating measures for improvement. BMC Fam Pract 2003; 4:18. http://dx. doi.org/I0.II86/147/-2296-4-9

36 Anderson N, Fuller R, Dudley N. 'Rules of thumb' or reflective practice? Understanding senior physicians' decision-making about anti-thrombotic usage in atrial fibrillation. QJM 2007; 100:263-9. http://dx.doi.org/l0.1093/qjmed/hcm016

37 Bajorek BV, Krass I, Ogle SJ et al. Warfarin use in the elderly: the nurses' perspective. Aust J Adv Nurs 2006; 23:19-25.

38 Dantas GC, Thompson BV, Manson JA et al. Patients' perspectives on taking warfarin: qualitative study in family practice. BMC Fam Pract 2004; 5: I5. http://dx.doi.org/10.1 I86//47/-2296-5-15

39 Robinson A, Thomson R. Variability in patient preferences for participating in medical decision making: implications for the use of decision support tools. Qual Health Care 200 I; 10: 34-8. http:// dx.doi.org/10.1136/qhc.0100034

40 Thomson RG, Eccles MP, Steen NI et al. A patient decision aid to support shared decision-making on anti-thrombotic treatment of patients with atrial fibrillation: randomised controlled trial. Qual Saf Health Care 2007; 16:216-23. http://dx.doi.org/10.1/36/ qshc.2006.01848

4I Gattellari M,Worthington JM, Zwar NA et al. Barriers to using warfarin in non-valvular atrial fibrillation. BMJ 2006; 332:303-4. Erratum in BMJ 2006; 332:396. http://dx.doi.org/10.1 I36/bmj.332.7536.303-b

42 Choudhry NK, Anderson GM, Laupacis A et al. Impact of adverse events on prescribing warfarin in patients with atrial fibrillation: matched pair analysis. BMJ 2006; 332: |4I-5. http://dx.doi.org//0.1 I36/ bmj.38698.709572.55

43 Pell JP, Alcock J. Monitoring anticoagulant control in general practice: comparison of management in areas with and without access to hospital anticoagulant. Br J Gen Pract 1994; 44:357-8. 
44 Bungard TJ, Ghali WA, McAlister F et al.The relative importance of barriers to the prescription of warfarin for nonvalvular atrial fibrillation. Can J Cardiol 2003; 19:280-4.

45 Olesen JB, Lip GY, Hansen ML et al.Validation of risk stratification schemes for predicting stroke and thromboembolism in patients with atrial fibrillation: nationwide cohort study. BMJ 20II; 342:dI24. http://dx.doi.org/I0.II36/bmj.dI 24

46 Mant J, Hobbs FD, Fletcher $\mathrm{K}$ et al. Warfarin versus aspirin for stroke prevention in an elderly community population with atrial fibrillation (the Birmingham Atrial Fibrillation Treatment of the Aged Study, BAFTA): a randomised controlled trial. Lancet 2007; 370:493-503. http://dx.doi.org/10.1016/S0 I40-6736(07)6 I233-I

\section{Other references retrieved that may contribute to development of quantitative method}

I Cowan C, Fay M, Griffith K et al. Anticoagulation in AF. Anticoagulation uptake remains poor in high risk patients. BMJ 20I I; 342:d I $53 .{ }^{2}$

Olesen et al validate the predictive value of the $\mathrm{CHA}_{2} \mathrm{DS}_{2}$ VASc score among patients admitted to hospital with $A F$, showing its superiority to the traditional $\mathrm{CHADS}_{2}$ score in identifying patients at low risk of stroke. ${ }^{45}$ However, even among patients with identified AF and identifiable risk factors, the uptake of anticoagulation in the UK continues to be worryingly low.

A primary care database interrogation tool developed by the West Yorkshire Cardiac Network was used to calculate $\mathrm{CHADS}_{2}$ score among patients with AF. It was applied nationally in over 310 practices in 48 primary care trusts in more than 47,000 patients with AF; only $51.4 \%$ of patients at high risk $\left(\mathrm{CHADS}_{2}>\mathrm{I}\right)$ were receiving warfarin. A cohort of 228,000 patients in York Primary Care Trust were assessed for contraindications to warfarin. Only $27 \%$ of the untreated high-risk population had absolute contraindications to warfarin. The most common reason for not giving warfarin to them was the reluctance of physicians to prescribe it. Thus the barrier to prescribing anticoagulants even to high-risk patients must be overcome. Ironically, the current iteration of the Quality and Outcomes Framework for $A F$ does not indicate the value of any risk stratification. Even among high-risk patients, it rewards treatment with aspirin or warfarin equally, despite considerable evidence of the superiority of warfarin at no excessive risk of bleeding. ${ }^{46}$ The undoubted value of a $\mathrm{CHA}_{2} \mathrm{DS}_{2}$ VASc score in detecting patients at low-risk should not deflect from the main task of appropriately treating high-risk groups, however they are identified.

2 Azoulay L, SimonT et al. Optimal warfarin anticoagulation and the prevention of stroke in patients with atrial fibrillation: A population-based study. Euro $H J$ Conference (Start: 28/08/20IO Conference End: 0I/09/2010): European Society of Cardiology, ESC Congress 2010 Stockholm Sweden.
Purpose: The objective of this study was to quantify the association between optimal warfarin anticoagulation, as determined by time in therapeutic range, and the incidence of stroke in patients newly diagnosed with $A F$, in the natural setting of clinical practice.

Methods: We conducted a population-based cohort study with a nested case-control analysis within the United Kingdom's General Practice Research Database population. The cohort included all patients at least 18 years of age with a first ever diagnosis of AF between I January 1993 and 3I December 2008. During follow-up, all subjects who experienced a stroke were identified as cases. Up to ten controls selected from the cohort were matched to each case based on year of birth, sex, date of cohort entry, and duration of follow-up. A new algorithm, incorporating both international normalised ratios (INR) and warfarin prescription information, was created to categorise patients according to their time in therapeutic range. Conditional logistic regression was used to estimate rate ratios (RR) of stroke associated with the use of warfarin and time spent in different levels of anticoagulation. All RRs were adjusted for $\mathrm{CHADS}_{2}$ score and other relevant confounders, which included body mass index, excessive alcohol use and smoking status.

Results: The cohort comprised 74,095 patients newly diagnosed with AF, of whom 5,996 experienced a stroke during a mean follow-up of 3.8 years. The overall stroke rate was 21.3 per 1000/year. Patients currently exposed to warfarin were at a decreased risk of stroke compared with patients who were never exposed to warfarin (adjusted RR: $0.63,95 \% \mathrm{Cl}: 0.58,0.68)$. When current warfarin users were categorized according to their level of anticoagulation, only those within therapeutic range (INRs between 2 and 3) were at a decreased risk of stroke (adjusted RR: $0.61,95 \% \mathrm{Cl}: 0.52$, 0.72), while no association was found for those below or above therapeutic range (adjusted RR:0.85, 95\% Cl:0.68, I.06 and adjusted RR: $0.93,95 \% \mathrm{Cl}: 0.69, \mathrm{I} .25$, respectively).

Conclusions: The results of this large population-based study provide further evidence that warfarin therapy decreases the risk of stroke in patients with AF. However, this decreased risk was only observed in patients within the recommended therapeutic range.

3 Dobrzanski S, Shaw N.An audit to determine if general practitioners are aware of warfarin treatment when this drug is routinely provided by a hospital anticoagulant clinic. Int J Pharm Pract Conference (Start: 06/09/2009; Conference End: 09/09/2009): British Pharmaceutical Conference 2009 Manchester United Kingdom.

Introduction and objectives: Whenever new GP-led anticoagulant clinics were planned to take over the care of well-controlled patients who had previously obtained their supply of warfarin from a pharmacy-led hospital anticoagulant clinic, it was found that the lists of patients 
MR Fay, C Montaňa

ANNEX A Barriers to warfarin use (reproduced from Ingelgard et al ${ }^{14}$ ).

\begin{tabular}{|c|c|}
\hline Patient medical characteristics & Patient capabilities \\
\hline $\begin{array}{ll}\text { - } & \text { Minor bleeding episode within past three months } \\
\text { - } & \text { Severe bleeding episode within past three months } \\
\text { - } & \text { Severe bleeding episode }>\text { three months ago } \\
\text { - } & \text { Concurrent use of non-steroidal anti-inflammatory drugs } \\
\text { - } & \text { Current alcohol dependence or abuse } \\
\text { - } & \text { Currently in sinus rhythm and receiving an } \\
\text { - } & \text { Difficulty in obtaining venous access } \\
\text { - } & \text { Hill risk (e.g. history of falls, uncontrolled epilepsy, etc.) } \\
\text { - } & \text { Hepatic disease secondary to alcoholism } \\
\text { - } & \text { Hepatic disease not due to alcoholism } \\
\text { - } & \text { Infrequent paroxysmal AF } \\
\text { - History of labile/fluctuating International Normalized } \\
\text { - } \text { Ratio (INRs) } \\
\text { Overdose difficult to treat } \\
\text { - Patient taking medications that may interact with warfarin } \\
\text { Patient taking herbal therapies that may interact with } \\
\text { - } \quad \text { Renarin disease requiring haemodialysis } \\
\text { Stroke prophylaxis not primary concern in patient's } \\
\text { overall treatment goals }\end{array}$ & 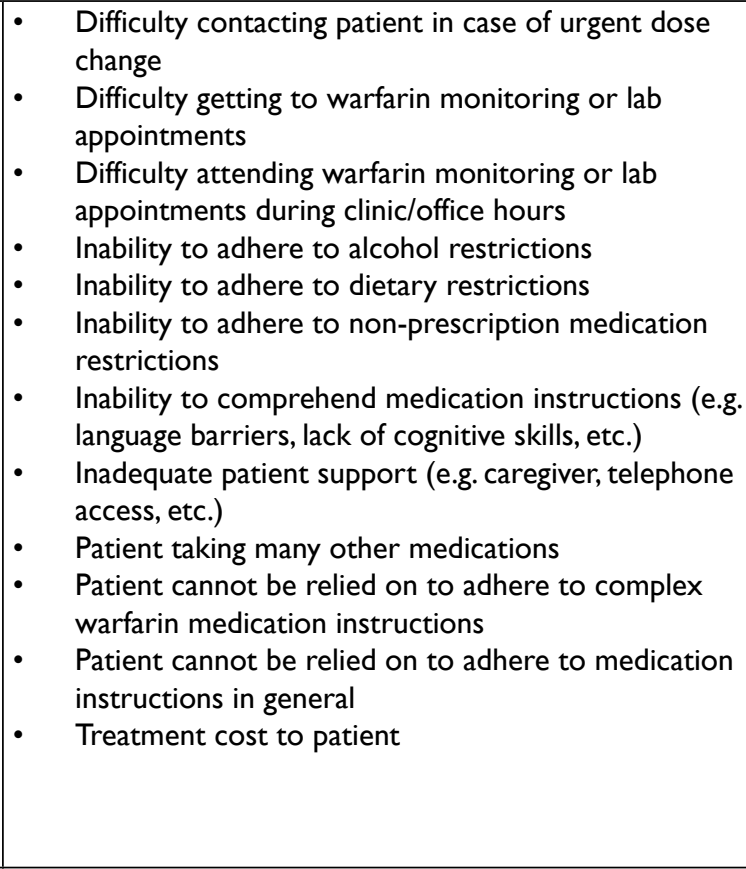 \\
\hline Patient preference & Healthcare system barriers \\
\hline $\begin{array}{ll}\text { - } & \text { Patient concerned about risk of bleeding } \\
\text { - } & \text { Patient difficult to motivate about general preventive } \\
\text { measures } & \text { Patient concerned about adverse effect on quality of life } \\
\text { or lifestyle } \\
\text { - } & \text { Stroke prophylaxis a low priority for patient } \\
\text { Patient unwilling to undergo repeat testing }\end{array}$ & $\begin{array}{ll}\text { - } & \text { Risk of litigation } \\
\text { - } & \text { Loss of continuity of care if patients managed in an } \\
\text { - } & \text { Delay in lab reporting } \\
\text { - } & \text { Inadequate reimbursement } \\
\text { - } & \text { Causes an increased office workload } \\
\text { - } & \text { therapy of experience and training to manage warfarin } \\
\text { Lack of anticoagulation clinics or other specialist } \\
\text { monitoring services }\end{array}$ \\
\hline
\end{tabular}

identified in each GP practice as taking anticoagulants were different to those held by the hospital. GPs were not sure which of their patients took warfarin. When clinical responsibility for anticoagulant therapy is transferred, a poor communication system has been identified as an area of risk. Because the hospital routinely accessed the main, locally used electronic GP prescribing programme (SystmOne) for confirming medication histories, the hospital pharmacy clinic was asked by primary care to make use of this access to try to identify reasons for the mismatch.

Method: The audit involved accessing GP electronic records either in hospital or at the GP practice after a period of at least four weeks following each new patient referral by the hospital to the pharmacy-led clinic. A check was made to confirm that practices had received and registered information sent by the hospital about warfarin in the form of consultant discharge summaries, discharge letters and outpatient clinic letters. The main 'repeat template' prescribing field of the electronic record (used to generate repeat prescriptions) was investigated to determine if the practice had highlighted that warfarin was being provided by a third party and that the record relating to anticoagulation was comprehensive. This included checking that the practice was aware of the duration of anticoagulant therapy and in patients taking aspirin, determining if this had stopped or continued to be prescribed.

Results and discussions: From a sample of 84 referrals by the hospital to the pharmacy clinic, 51 patients belonged to GP practices using SystmOne. From this latter group, there was only one instance where hospital communications had not been scanned onto the electronic record by a GP practice. Nevertheless, in 25 cases (49\%), warfarin had not been entered on the repeat template, possibly because the GP was not being asked to prescribe the drug. This meant that as details of warfarin use were consigned to less frequently accessed sections of the electronic record, the GP might easily overlook that anticoagulation had begun. Information about the duration of warfarin treatment was invariably absent. There were 18 cases where patients had remained on aspirin unintentionally and two instances where the hospital had not indicated if it should stop. Overall, 
information about warfarin was missing, not readily accessed or incomplete in $\mathbf{8 2 . 4 \%}$ of cases. As there was no hospital electronic link with non-SystmOne practices, it is not clear if a similar picture would be found there.

Conclusions: Where GPs do not have to prescribe warfarin because it is already being provided in hospital, then there is a risk that their practice records about anticoagulation may remain incomplete. Retinoids, certain drugs for metabolic diseases and oral chemotherapy may also exclusively be supplied by hospitals, and possibly GPs may similarly not always be aware of their use. Anticoagulant clinic pharmacists could themselves correct the GP electronic record, but this was not a solution for those practices with no electronic link to the hospital. Instead a form was introduced for GPs formally to acknowledge that warfarin was recorded on their patient's repeat template as being supplied by the hospital.

\section{ANNEX B}

Critique of Ingelgard et $\mathrm{al}^{16}$ paper

- This paper provides a useful summary of known barriers to warfarin use, although I suspect very little of the literature reviewed was UK-based.

- The authors identify 4I barriers, discussed under four broad themes: I) patient medical characteristics; 2) healthcare system factors; 3) patient capability and 4) patient preference.

- The extent to which each of the identified themes influenced prescribing decisions was measured at two levels by 35 physicians; physician level ( 10 point likert scale listing identified barriers) and patient level (barriers scaled as non-critical to critical).

- They attempt to measure physicians reluctance to prescribe on a general level and their actual behaviour with respect to anticoagulant prescriptions in their own AF patients, which should provide for a better understanding of attitudes vs. reality. However, there are several problems with their method that make the interpretation of their results difficult:

» They contextualise the limitations of previous studies i.e. non-structured approaches for eliciting barriers and use of clinical vignettes without the use of patient-level data. However, they use clinical vignettes in their measures (i.e. doctors are asked questions on the reasons for not prescribing warfarin based on AF patient medical records provided by the research team). Less than half of their sample ( $N=35$ physicians; 15) provided data about their AF patients. This was stated as two per physician although only 24 cases were recorded. Does this mean that there were actually 12 physicians or that some physicians had only one patient on their caseload with AF (and would this be typical?).
1) The factor that most strongly influenced physicians decisions not to prescribe was severe bleeding $<3$ months ago $(N=30$, don't know what happened to other five) while the most prevalent critical barriers (not sure what is meant by this or how this was perceived by physicians) in specific AF patients was patient unwilling to undergo repeat testing $(\mathrm{N}=24$, only $68 \%$ of sample, again don't know why number reduced).

1) It is not clear how many of the responses to patient level data were to actual physicians' own patients or those generated by the research team - so cannot tell if this data is dominated by responses to clinical vignettes.

» In patient-level data, a bleeding episode $>3$ months ago is reported as a barrier as often there is difficulty in getting to monitoring appointments. It is difficult to understand how a medical characteristic would be just as influential as a transport issue in a prescribing decision. It may be that wide variation in physicians' prior experiences accounts for these two different barriers seemingly having equal precedence. Interestingly, severe bleeding episode within the past three months was reported less frequently $(3,12.5 \%)$ as a critical barrier compared to patients unwillingness to undergo repeat testing $(7,29.2 \%)$. This may be because physicians recognised their patient characteristics in the scenarios.

» They state that physicians say they work around healthcare system barriers. This was because none of these barriers appeared among the 15 barriers of most concern to clinicians. These barriers were thought to be rare (e.g. lack of reimbursement for phone follow-up with a patient and increased office workload) and were unlikely to prevent a patient from receiving warfarin. It is difficult to consolidate this with findings from other studies where these barriers are instrumental in prescribing decisions for patients. At the same time, they list lack of experience and training in managing warfarin therapy as a barrier that physicians work around, and it is difficult to see how a physician lacking the knowledge and skill would be able to initiate a prescription, or openly admit to lack of competence in this area (particularly when they have volunteered to take part in the study).

» There are wide variations in individual clinicians' rating across all barriers.

» State that there are 15 barriers of most concern, although only 14 are listed.

» Don't state how other barriers rated in relation to the 14 concerned.

I Some of the categorisation of barriers may be different in the UK. For example, they list 
MR Fay, C Montaňa

difficulty in getting to warfarin monitoring or lab appointments as a patient capability; in the UK this may be seen as healthcare system factor. Likewise, other capabilities may really be related to the costs incurred to the patient in non-UK healthcare systems.

॥ They list 'patient unwilling to undergo repeat testing' as a patient preference, but again this may be related to costs incurred to the patient.

» I am not certain which patient medical characteristics are actual contraindications or imposed by the physicians (fear of litigation may influence categorisation for example). They also list stroke prophylaxis as not being a primary concern in patients' overall treatment goals (this must be influenced by the nature of the relationship with the patient).

॥ Physician characteristics may be biased. For example, the reported percentage of $\mathrm{AF}$ patients receiving warfarin was $68.8 \%$ (SD 19.5). However literature indicates that up to $60 \%$ of patients indicated for warfarin do not receive it. Their percentages of patients using different medications are erroneous (102\%).
॥ They state that one of their aims is to understand underlying reasons for several abstract barriers in the literature such as non-compliance, age and dementia. However they do not address this in their results and discussion.Age is believed to be an independent barrier and not fully explained by barriers already on the list - not sure what they mean by this.

» The authors conclude that patient preference is a major factor limiting warfarin use. Precise reasons for this were not explored, and it is not clear to what extent these barriers exist within our healthcare system. 